Article

\title{
Life cycle Assessment of hydrogen production via natural gas steam reforming vs. biomass gasification
}

\author{
Peiran Zhao ${ }^{1}$, Abbas Tamadon ${ }^{2, *}$ and Dirk Pons ${ }^{2, *}$ \\ 1 Department of Chemical and Process Engineering, University of Canterbury, Private Bag 4800, Christchurch \\ 8020, New Zealand; peiran.zhao@pg.canterbury.ac.nz \\ 2 Department of Mechanical Engineering, University of Canterbury, Christchurch 8041, New Zealand; \\ * Correspondence: abbas.tamadon@canterbury.ac.nz (A.T); dirk.pons@canterbury.ac.nz (D.P)
}

\begin{abstract}
CONTEXT- Energy is widely involved in human activity and corresponding emissions of $\mathrm{SO}, \mathrm{NOx}$ and $\mathrm{CO}_{2}$ from energy generation processes affect global climate change. Clean fuels are desired by society because of their reduced greenhouse gas emissions. Hydrogen is once such candidate fuel. Much hydrogen is produced from fossil fuel, with biomass being an alternative process. OBJECTIVE- The project compared the environmental impact of hydrogen production by natural gas steam reforming vs. biomass gasification. METHOD-Environmental impact was calculated from the input and output data from life cycle inventory analysis. The impact assessment was focused on greenhouse gas emission, acidification, and eutrophication. Models of the two processes were developed and analysed in OpenLCA. The agribalyse database was used to connect inventory flow data to environmental impacts. FINDINGS- For all three metrics, biomass gasification had lower impacts than natural gas steam reforming, sometimes by large margins. For biomass gasification the silica sand production contributes most to all three impact categories, whereas for natural gas steam reforming it is the LPG extraction.
\end{abstract}

Keywords: Life Cycle Assessment; hydrogen production; natural gas steam reforming; biomass gasification

\section{Introduction}

\subsection{Context}

The total global energy consumption was 9938 millions of tons of oil equivalent (Mtoe) in 2018 which consisted of 10\% from coal, 16.2\% from natural gas and $40.8 \%$ from oil [1]. Energy security, affordability and reliability have become crucial for societies and their governments. Energy is widely involved in every human activity and corresponding emissions of $\mathrm{SO}, \mathrm{NOx}$ and $\mathrm{CO}_{2}$ from energy generation process affect global climate change [2].

Clean fuels are desired by society because of lower greenhouse gas emissions. Hydrogen is one candidate for a clean fuel. However, current production methods are primarily based on fossil fuel, with resulting challenges for emissions. Hydrogen can also be produced from biomass. This is a potentially attractive route as the feedstock can be residue from forestry and agricultural industries.

In this project, the life cycle of hydrogen production from biomass gasification and hydrogen production from natural gas were analyzed based on the ISO 14040 method. The system boundary includes raw material acquisition, factory operation (required feedstock preparation, producing operation and downstream processing like gas cleaning), and transportation. The result of the life cycle analysis for this project is dependent on the input parameters of consumption of coal, natural gas, oil, water, and electricity from all related processes within the boundary defined. The environmental impacts were determined by output parameters such as emissions of $\mathrm{SO} x, \mathrm{NOx}$ and $\mathrm{CO}_{2}$.

\subsection{Steam production process}


Hydrogen production from natural gas steam reforming is the most popular method, supplying almost 50\% of the world's hydrogen [13]. Usually, raw natural gas is pre-treated through hydrogenation where all sulphur compounds in the raw supply are converted to hydrogen sulphide, which is then removed [14]. The technology is mature and the processes well understood.

Natural-gas-steam-reforming is a catalytic process to produce hydrogen from hydrocarbon and steam and the conversion efficiency is between $74-85 \%$, see [15]. During steam methane reforming, methane and steam are converted to carbon monoxide and hydrogen, while during water gas shift reaction, carbon monoxide produced from steam methane reforming is further reacted with steam to produce more hydrogen and carbon dioxide [16]. Natural gas steam reforming is an endothermic reaction which requires a large amount of energy input to achieve the desired temperature condition [17].

The hydrogen is separated and purified after coming out of the water gas shift reactor. Preferential oxidation and pressure swing adsorption are two possible methods for purification of hydrogen. Preferential oxidation can reduce the carbon monoxide presence in the final hydrogen product which purifies the hydrogen, and pressure swing adsorption can provide much higher concentrated hydrogen, up to $99.9 \%$ [18].

The environment emissions from steam processes based on methane fossil fuel are about $0.3-0.4 \mathrm{~m}^{3}$ carbon dioxide per $\mathrm{m}^{3}$ of hydrogen [15]. For hydrogen produced from steam reforming, the consumption of natural gas is about $3.5 \mathrm{~kg}$ per $\mathrm{kg}$ of hydrogen produced, and the consumption of water is about $1.9 \mathrm{~kg}$ per $\mathrm{kg}$ of hydrogen production [19]. The coal consumption is about $36.7 \mathrm{~g}$ per $\mathrm{kg}$ of hydrogen produced (data for Spain), and the oil consumption is about $17.5 \mathrm{~g}$ per $\mathrm{kg}$ of hydrogen production (assuming 2000 $\mathrm{km}$ land transportation is required) [20]. In general, the electricity usage is about $1.13 \mathrm{MJ}$ per $\mathrm{kg}$ of hydrogen produced [21]. The literature on emissions is summarized in Table 1.

Table 1. Greenhouse gas emission summary from literature [6] [19] [20] [22].

\begin{tabular}{|c|c|c|c|c|}
\hline System & Boundary & Process involved & $\mathrm{CO}_{2}$ emission & $\mathrm{CH}_{4}$ emission \\
\hline \multirow{4}{*}{$\begin{array}{c}\text { Hydrogen production } \\
\text { from steam reforming } \\
\text { of natural gas }\end{array}$} & \multirow{4}{*}{ Cradle to grave } & Construction & $41.85[\mathrm{~g} / \mathrm{kg} \mathrm{H} 2]$ & \\
\hline & & $\begin{array}{c}\text { Natural gas production } \\
\text { and transport }\end{array}$ & 299.18 [g/kg H2] & 59.8 [g/kg H2] \\
\hline & & Electricity generation & 261.53 [g/kg H2] & \\
\hline & & Operation & $8756.1[\mathrm{~g} / \mathrm{kg} \mathrm{H} 2]$ & \\
\hline $\begin{array}{c}\text { Hydrogen production } \\
\text { from steam reforming } \\
\text { of natural gas }\end{array}$ & Cradle to grave & $\begin{array}{l}\text { Biomass production and } \\
\text { transportation } \\
\text { Gasification } \\
\text { Electricity generation and } \\
\text { electrolysis } \\
\text { Gas cleaning } \\
\end{array}$ & $7.58[\mathrm{~kg} / \mathrm{kg} \mathrm{H} 2]$ & $86.4[\mathrm{~g} / \mathrm{kg} \mathrm{H} 2]$ \\
\hline $\begin{array}{c}\text { Hydrogen production } \\
\text { from steam reforming } \\
\text { of natural gas }\end{array}$ & Cradle to grave & $\begin{array}{l}\text { Biomass production and } \\
\text { transportation } \\
\text { Gasification } \\
\text { Electricity and steam } \\
\text { generation } \\
\text { Gas cleaning } \\
\end{array}$ & $\begin{array}{r}0 . \\
{[\mathrm{kg} \text { of } \mathrm{CO}}\end{array}$ & \\
\hline $\begin{array}{c}\text { Hydrogen production } \\
\text { from steam reforming } \\
\text { of natural gas }\end{array}$ & Cradle to grave & $\begin{array}{c}\text { Biomass production and } \\
\text { transportation } \\
\text { Gasification } \\
\text { Electricity and steam } \\
\text { generation } \\
\text { Gas cleaning } \\
\end{array}$ & $10.66[\mathrm{~kg} / \mathrm{kg} \mathrm{H} 2]$ & $146.3[\mathrm{~g} / \mathrm{kg} \mathrm{H} 2]$ \\
\hline
\end{tabular}




\subsection{Biomass gasification process}

Biomass gasification is a thermal conversion process of producing various kinds of chemicals from biomass feedstock. The produced fuel from gasification can be further used for heating through combustion or used as feedstock for production of other types of chemicals and liquid fuel. Before biomass is fed into the gasifier, pre-treatment must be done to drop the moisture content and break the fibrous structure [3]. Currently, there are three types of mainstream gasification technologies, these being fixed bed, fluid bed and entrained flow gasification. The fixed bed gasification is usually applied for small scale operation where biomass is gasified by a downdraft or updraft gasification medium such as air. Fluid bed gasification includes bubbling and circulating fluidized bed processes, and is suitable for medium scales. Entrained flow gasification is mainly used for coal and petroleum based feedstock [4]. In general, the product from biomass gasification is called syngas and is a mixture of methane, carbon monoxide, hydrogen, carbon dioxide, tars, hydrogen chloride, hydrogen sulphide, ammonia [3]. From the aspect of producing combustible fuel, methane, carbon monoxide and hydrogen are the desired product while the rest of the components in the producer gas are unwelcome contaminants.

Hydrogen production from biomass gasification involves three major parts: biomass pre-treatment, syngas generation by gasification, and hydrogen production. Biomass is pre-dried before gasification and the moisture content of biomass is reduced to less than $5 \%$ with temperature conditions between $100{ }^{\circ} \mathrm{C}$ and $200{ }^{\circ} \mathrm{C}$ [7]. Typical heat sources for drying are hot air and steam. The efficiency of drying with air as a heat source is less than $50 \%$ when the temperature is below $160{ }^{\circ} \mathrm{C}$ and efficiency increases dramatically at higher temperature conditions [8]. However, volatile compounds such as terpenes are released from wood at high drying temperatures [9] which leads to problems in purification of drying air. Hence a desired drying temperature range is usually around $100{ }^{\circ} \mathrm{C}$ to $130{ }^{\circ} \mathrm{C}$ [10]. Pre-treated biomass is fed into the gasifier to produce syngas. After biomass gasification, hydrogen can be produced from various combined technologies. For example, hydrogen can be produced by combing syngas with catalytic steam reforming and water swift reaction or produced from electrolysis of water where the electricity is generated from syngas by the combined cycle method [5].

A circulating fluidized bed gasifier is one option for biomass gasification. Kalinci et al conducted a life cycle assessment of biomass gasification based on the circulating fluidized bed gasifier [11]. In their study, wood biomass particles were dried first and fed into the gasifier, where syngas was produced. Syngas was further treated with tar decomposition and a sulphur removal process. The clean syngas was finally sent into a water gas shift reactor for hydrogen production. The produced gas from the water gas shift reactor was pumped into a pressure swing adsorption unit, where hydrogen with purity at $99.9 \%$ was produced. The electricity supply was $0.49 \mathrm{MJ} / \mathrm{s}$ and the diesel supply $0.44 \mathrm{MJ} / \mathrm{s}$ during the pre-treatment process, the biomass feeding rate $10.1 \mathrm{~kg} / \mathrm{s}$, water feeding rate $16.731 \mathrm{~kg} / \mathrm{s}$ for production of $62.52 \mathrm{MJ} / \mathrm{s}$ hydrogen and no extra power was needed during gasification since the system can convert the energy in steam to electric energy through various turbine systems [11]. Sand can be used as additional bedding material in the gasifier to increase hydrogen production efficiency. Yaser et al concluded that the bed fluidisation material provides a flowrate of $27 \mathrm{~kg}$ per $\mathrm{kg}$ of dry biomass and a steam rate of $0.4 \mathrm{~kg}$ per $\mathrm{kg}$ of dry biomass to produce 18.9 tonne of hydrogen per hour [12]. Koronesos et al indicated that the gas composition after the shift reaction was $61 \%$ hydrogen, $34.1 \%$ carbon dioxide, $2.4 \%$ methane, $1.1 \%$ carbon monoxide. Around $77 \%$ of the hydrogen can be recovered after the pressure swing absorption, and is further liquefied [5]. 
The greenhouse gas emission of hydrogen production from biomass is much lower than hydrogen production from fossil fuel since the released carbon dioxide during biomass gasification is re-captured by the plants during growth [5]. Koroneos et al suggest that the greenhouse emission of hydrogen production from biomass gasification is $75 \%$ lower than fossil fuel [6]. The literature on greenhouse gas emissions is summarized in Table 2.

Table 2. The Greenhouse gas emission summary from literature [5] [6] [12].

\begin{tabular}{|c|c|c|c|}
\hline System & Boundary & $\begin{array}{l}\text { Process involved } \\
\end{array}$ & $\mathrm{CO}_{2}$ emission \\
\hline $\begin{array}{l}\text { Hydrogen production } \\
\text { from biomass gasification } \\
\text { with steam reforming }\end{array}$ & Cradle to grave & $\begin{array}{c}\text { Biomass production and transportation } \\
\text { Gasification } \\
\text { Reforming and purification } \\
\text { Liquefaction }\end{array}$ & $\begin{array}{c}1.4 \times 10^{5} \\
{[\mathrm{~kg} \mathrm{CO} 2 \mathrm{eq} / \mathrm{TJ} \mathrm{H} 2]}\end{array}$ \\
\hline $\begin{array}{c}\text { Hydrogen production } \\
\text { from biomass gasification } \\
\text { with electrolysis }\end{array}$ & Cradle to grave & $\begin{array}{c}\text { Biomass production and transportation } \\
\text { Gasification } \\
\text { Electricity generation and electrolysis } \\
\text { Gas cleaning }\end{array}$ & $\begin{array}{c}2 \times 10^{4} \\
{[\mathrm{~kg} \mathrm{CO} 2 \mathrm{eq} / \mathrm{TJ} \mathrm{H} 2]}\end{array}$ \\
\hline $\begin{array}{l}\text { Hydrogen production } \\
\text { from biomass gasification } \\
\text { with carbon capture system }\end{array}$ & Cradle to grave & $\begin{array}{c}\text { Biomass production and transportation } \\
\text { Gasification } \\
\text { Electricity and steam generation } \\
\text { Gas cleaning } \\
\end{array}$ & $\begin{array}{c}12 \\
{\left[\mathrm{CO}_{2} \text { eq } \mathrm{kg} / \mathrm{kg} \mathrm{H} 2\right]}\end{array}$ \\
\hline $\begin{array}{c}\text { Hydrogen production } \\
\text { from biomass gasification } \\
\text { without carbon capture system }\end{array}$ & Cradle to grave & $\begin{array}{l}\text { Biomass production and transportation } \\
\text { Gasification } \\
\text { Electricity and steam generation } \\
\text { Gas cleaning }\end{array}$ & $\begin{array}{c}28 \\
{\left[\mathrm{CO}_{2} \text { eq } \mathrm{kg} / \mathrm{kg} \mathrm{H} 2\right]}\end{array}$ \\
\hline
\end{tabular}

\subsection{Existing approaches to assessing the lifecycle emissions}

The environmental consequences of hydrogen production have been discussed in the literature. Some studies include the construction of the plant, while others only focus on the operation. Different types of biomass have been studied, including wood and agricultural waste. Some studies include downstream carbon capture, others not. There are also variabilities in the processes, such as pressure swing and electrolysis.

The main emissions for hydrogen production are $\mathrm{CO}_{2}, \mathrm{~N}_{2} \mathrm{O}$ and $\mathrm{CH}_{4}$, while $\mathrm{NOx}$, $\mathrm{SO}_{2}$ and particle emissions have been included.

Impact categories are:

- Global warming: the indicator for this impact is equivalent $\mathrm{CO}_{2}$ based primarily on $\mathrm{CO}_{2}$, and $\mathrm{CH}_{4}$, with the addition of $\mathrm{N}_{2} \mathrm{O}$.

- Particle emissions: consequences of particle emissions, such as respiration problems, are not covered in the literature.

- Eutrophication: NOx emission to water is related to eutrophication

- Human health: The effect of NOx on human health and ozone has not been explicitly considered in the literature. Health effects on humans such as respiration are also not included.

- Acidification: $\mathrm{SO}_{2}$ is considered as a weighting factor for acidification emissions.

Some literature introduces the boundary concept "net $\mathrm{CO}_{2}$ emission" of the biomass gasification process which is equal to the difference between $\mathrm{CO}_{2}$ consumption during the biomass growth and $\mathrm{CO}_{2}$ generation during the gasification process while other research assumes all the $\mathrm{CO}_{2}$ generated during the gasification is consumed during biomass growth.

The following aspects of hydrogen production are poorly understood. First, there is a need to apply more comprehensive impact categories. Second, more comprehensive 
study is required on electricity sources since LCA of electricity usage is highly dependent on electricity generation technology, i.e. from renewable energy or from fossil fuel, and some hydrogen production plants have an electricity generation system embedded within the overall process. Third, technology variation in the overall process should be stated clearly so that the emission can be fully defined, i.e. sulphur emission reduces greatly when sulphuric removal pre-treatment is applied.

The purpose of this project is to compare the environmental impact from two methods in hydrogen production including hydrogen production from biomass gasification and hydrogen production from natural gas steam reforming. For both scenarios, the boundary covers cradle to grave. Hence, raw material acquisition, producing product, associated operations such as gas cleaning, and all related transportation activities were analysed.

\section{Materials and Methods}

\subsection{Life Cycle Inventory}

Life cycle assessment aims to evaluate the environmental impacts from the product, process and corresponding operations [5]. In this project, raw material collection, product manufacturing, waste management and associated transportation were included.

\subsection{Life Cycle Impact assessment}

The selected impact categories were global warming, eutrophication to fresh water and terrestrial acidification. These were selected based for the following reasons. Global warming is the most common component in Life Cycle Analysis, and it is also the most pressing issue from a societal perspective. Raw material from fossil fuel and biomass contains sulphur compounds which are released to the environment; thus, acidification is required in the LCA model. Nitrogen compounds are common in biomass, hence eutrophication to fresh water must be included.

Software OpenLCA (version 1.10.3) was applied with the agribalyse (v301_27052021) database to connect inventory flow data to environmental impacts.

\subsection{Data assumptions}

Inputs and outputs from the defined boundary system were identified, with the quantity of inventory flow based on the literature. All the data calculations were based on the production of $1 \mathrm{~kg}$ of hydrogen. The electricity was based on the Australian (AU) market.

There is an electricity generation process embedded within the biomass gasification process, so the plant can supply the energy by itself. The outlet emission of the biomass gasification process was estimated based on mass balance since emission data of a real plant was not discoverable.

The total transportation was assumed as $1000 \mathrm{~km}$ for the biomass gasification model. For the steam reforming process, we assumed the natural gas was transported to the plant by pipeline. However, construction of pipelines was not in the LCA boundary for this project. Transportation of the hydrogen product was assumed to be $1000 \mathrm{~km}$ in the steam reforming model.

The $\mathrm{CO}_{2}$ emission from acquisition of biomass was assumed to be nil since all the $\mathrm{CO}_{2}$ emission is absorbed during the growth of biomass. Inputs and outputs are listed in Tables 3 and 4 .

Table 3. Input and output of $1 \mathrm{~kg}$ hydrogen production from biomass, based on [23], [5]. Note that COD refers to chemical oxygen demand. The other stream variables are standard chemicals and not explained further. 


\begin{tabular}{|c|c|c|c|}
\hline Input/Output & Stream & Flow rate & Unit \\
\hline \multirow{3}{*}{ Input } & Biomass & 16.3 & $\mathrm{~kg}$ \\
\hline & Steam & 27 & $\mathrm{~kg}$ \\
\hline & Lorry transportation & 1000 & $\mathrm{~km}$ \\
\hline \multirow{12}{*}{ Output } & Air emission & & \\
\hline & $\mathrm{CO}_{2}$ & 0.4 & $\mathrm{~kg}$ \\
\hline & $\mathrm{CO}$ & 2 & $\mathrm{~g}$ \\
\hline & $\mathrm{CH}_{4}$ & 6 & $\mathrm{~g}$ \\
\hline & HCL & 0.4777 & $\mathrm{~g}$ \\
\hline & $\mathrm{N}_{2} \mathrm{O}$ & 0.03 & $\mathrm{~g}$ \\
\hline & $\mathrm{NO} x$ & 5 & $\mathrm{~g}$ \\
\hline & Particles & 86 & $\mathrm{~g}$ \\
\hline & $\mathrm{SO}_{2}$ & 1 & $\mathrm{~g}$ \\
\hline & Water emission & & \\
\hline & $\mathrm{H}^{+}$ & 0.00446 & $\mathrm{~g}$ \\
\hline & $\mathrm{COD}$ & 2 & $\mathrm{~g}$ \\
\hline
\end{tabular}

Table 4. Input and output of $1 \mathrm{~kg}$ hydrogen production from natural gas, based on [19], [20], [22].

\begin{tabular}{cccc}
\hline Input/Output & Stream & Flow rate & Unit \\
\hline \multirow{2}{*}{ Input } & Natural gas & 3.5 & $\mathrm{~kg}$ \\
& Steam & 18.8 & $\mathrm{~kg}$ \\
& Electricity & 1.13 & $\mathrm{MJ}$ \\
& Lorry transportation & 1000 & $\mathrm{~km}$ \\
\hline & Air emission & & \\
& $\mathrm{CO}$ & 7.58 & $\mathrm{~kg}$ \\
& $\mathrm{CO}$ & 1.71 & $\mathrm{~g}$ \\
& $\mathrm{CH}$ & 0.0864 & $\mathrm{~g}$ \\
& $\mathrm{HCL}$ & 0.0149 & $\mathrm{~g}$ \\
& $\mathrm{~N} 2 \mathrm{O}$ & 0.0179 & $\mathrm{~g}$ \\
& $\mathrm{NO}$ & 3.21 & $\mathrm{~g}$ \\
& $\mathrm{Particles}$ & 63.9 & $\mathrm{~g}$ \\
& $\mathrm{SO} \mathrm{C}_{2}$ & 1 & $\mathrm{~g}$ \\
& $\mathrm{Hydrocarbon}$ & 2.05 & $\mathrm{~g}$ \\
& $\mathrm{H}$ & 0.00075 & $\mathrm{~g}$ \\
& $\mathrm{COD}$ & 0.000599 & $\mathrm{~g}$ \\
\hline
\end{tabular}

\section{Results}

\subsection{Architecture of the LCA model}

The biomass gasification model involves four major parts, which are the acquisition of silica sand, acquisition of wood pellets, lorry transportation and acquisition of steam, see Figure 1. 


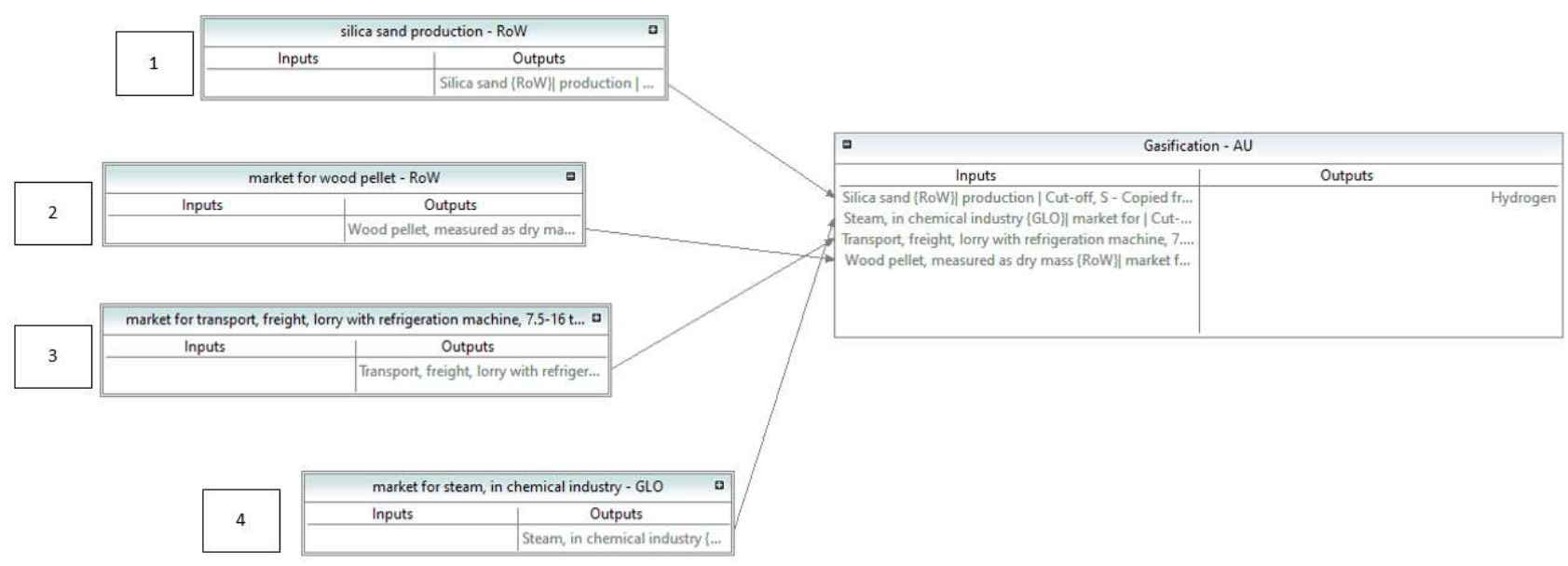

Figure 1. The construction of the LCA model for hydrogen production from biomass gasification.

The natural gas steam reforming model involves 4 major parts which are electricity in AU market, acquisition of natural gas, acquisition of steam and lorry transportation, see Figure 2.

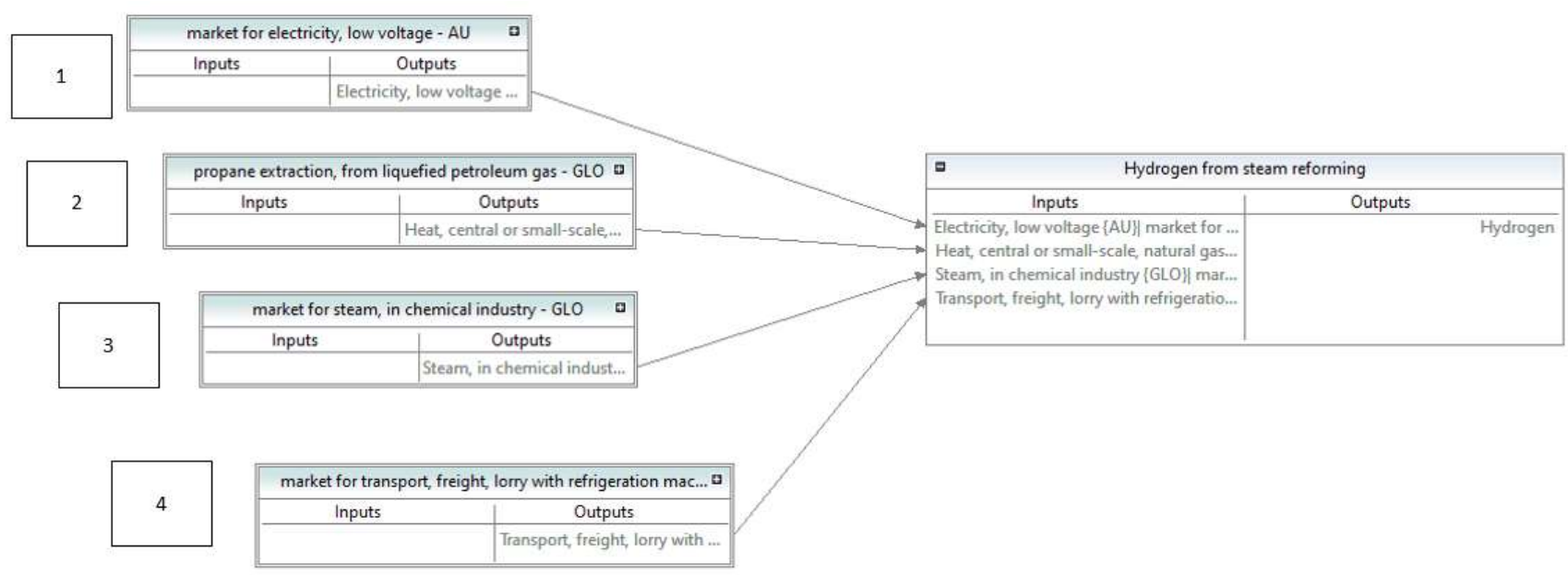

Figure 2. The construction of the LCA model for hydrogen production from natural gas steam reforming.

Impact metrics were as follows. Disability-adjusted life year (DALY) is the measurement of years lost due to health problems or environmental impacts. One DALY represents the loss of the equivalent of one year of full health. In this case, DALY is years lost due to global warming impacts on human health. Species, $\mathrm{Yr}$ represents ecosystem quality, which is the local species loss over time. In this case, species loss due to acidification and freshwater eutrophication were analysed.

\subsection{Results for biomass gasification}

The global warming of the Hydrogen production from biomass gasification is shown in Figure 3. The silica sand production is the main contributor. The results also show that the transportation can be considered negligible compared to the other variables. 


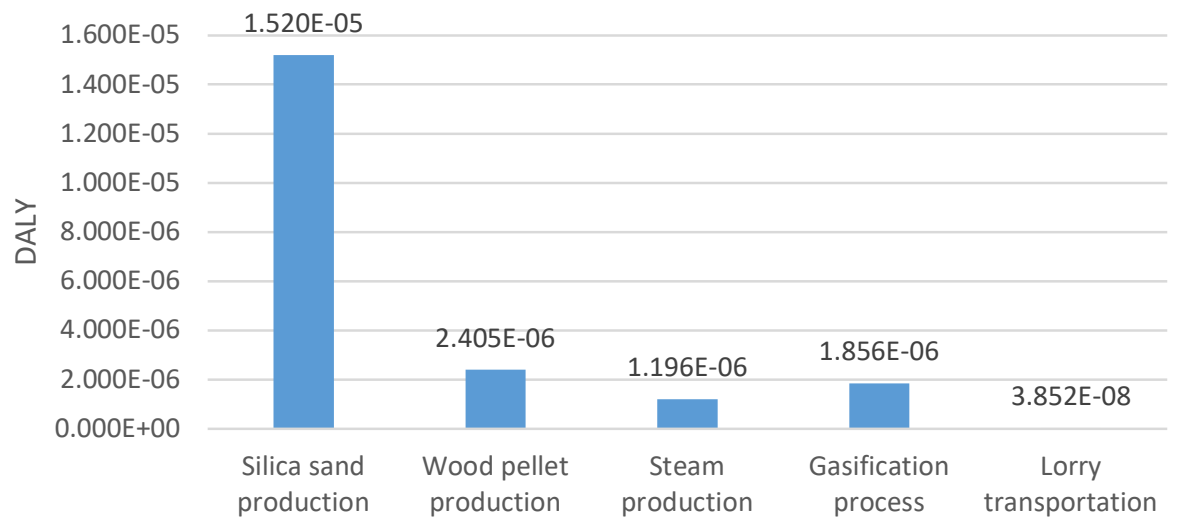

Figure 3. Global warming effect from hydrogen production from biomass gasification.

The Terrestrial acidification effect of the Hydrogen production from biomass gasification is shown in Figure 4. Clearly, the silica sand production again shows a significant portion of acidification effect compared to other categories observed in this scenario. Lorry transportation and gasification process however showed no major role in terrestrial acidification.

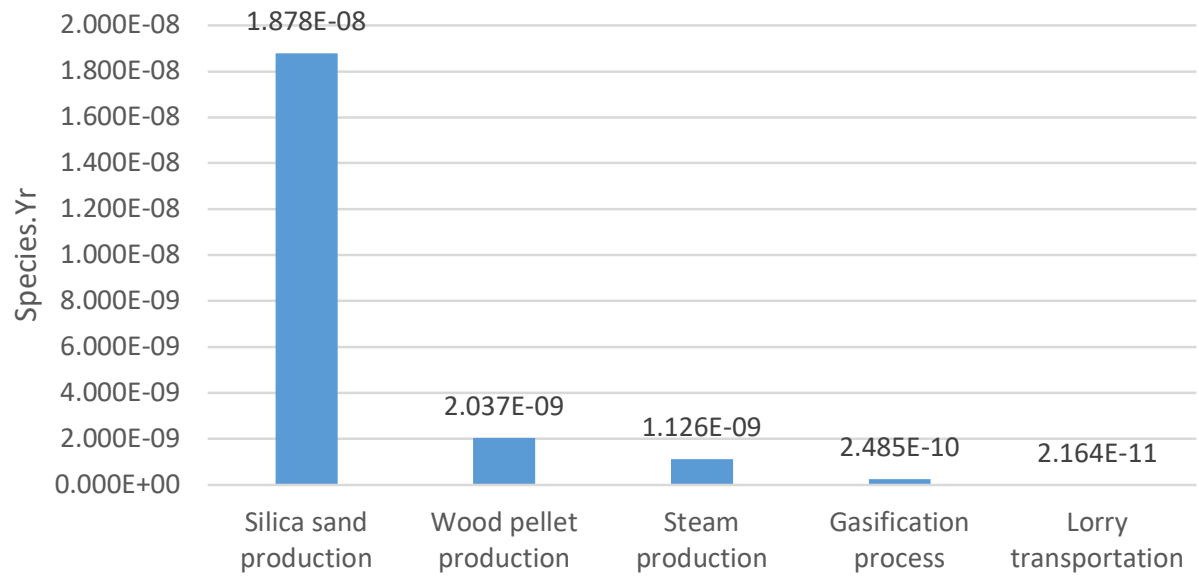

Figure 4. Terrestrial acidification effect from hydrogen production from biomass gasification.

The Freshwater eutrophication effect of the Hydrogen production from biomass gasification is shown in Figure 5. The silica sand production still represents the main portion of freshwater eutrophication, whereas the lorry transportation is minor. 


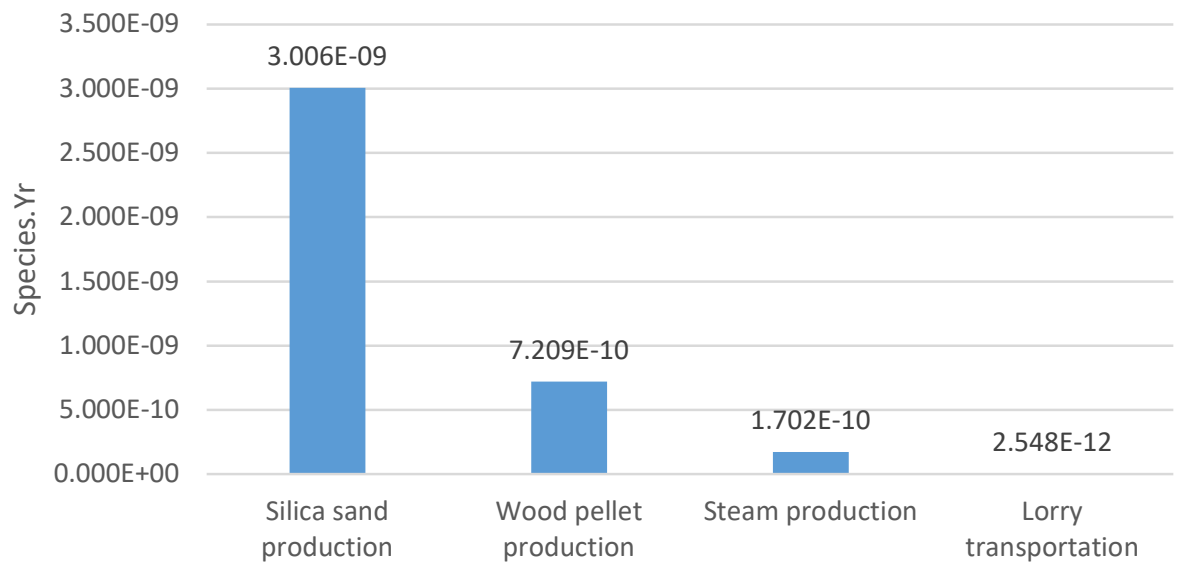

Figure 5. Freshwater eutrophication effect from hydrogen production from biomass gasification.

\subsection{Results for natural gas steam reforming}

The Global warming effect of the Hydrogen production from natural gas steam reforming is shown in Figure 6. Clearly, the LPG production makes the main contribution to global warming compared to other emission products. Furthermore, the role of $\mathrm{CH}_{4}$ steam reforming process is the second main effect between other four outputs.

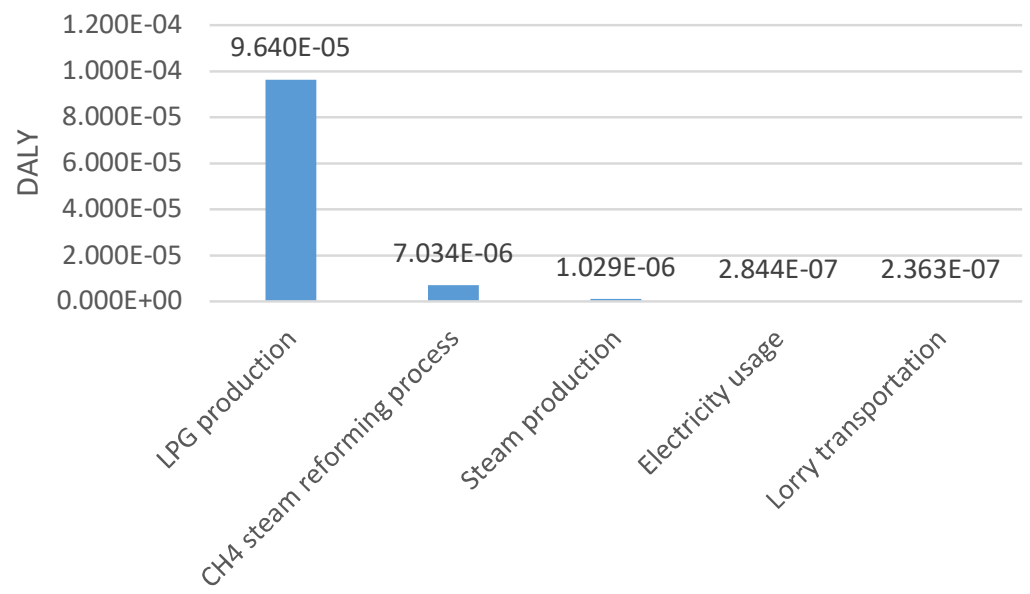

Figure 6. Global warming effect from hydrogen production from natural gas steam reforming.

The Terrestrial acidification effect of the Hydrogen production from natural gas steam reforming is shown in Figure 7. Similar to the results for global warming, the LPG production dominates. 


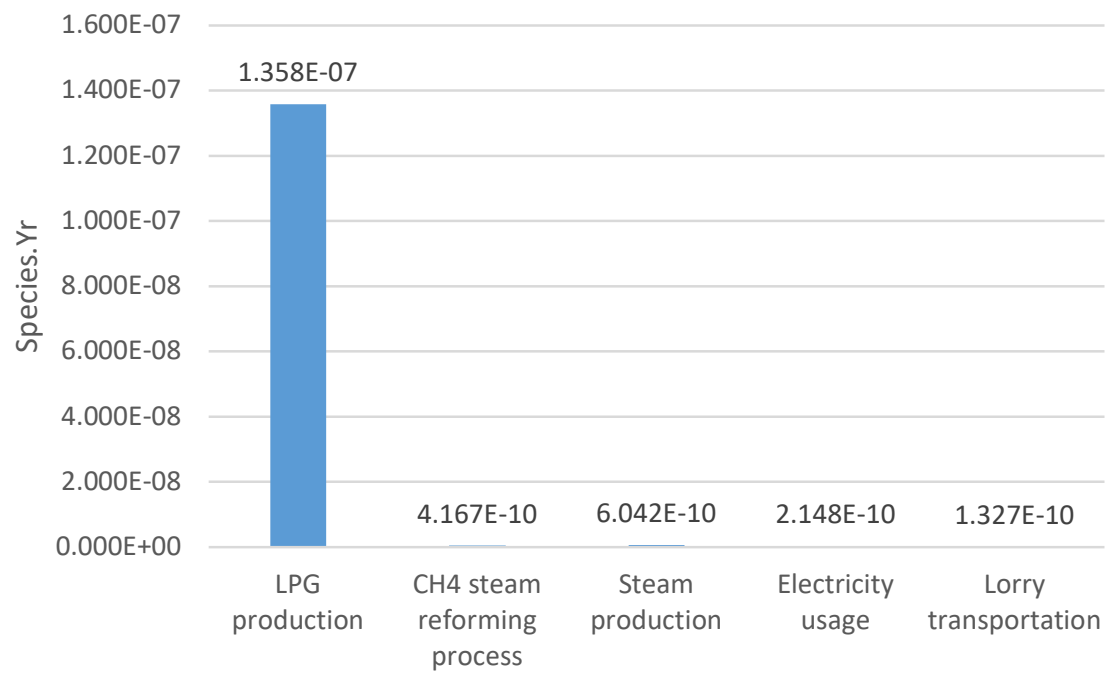

Figure 7. Terrestrial acidification effect from hydrogen production from natural gas steam reforming.

The Freshwater eutrophication effect of the Hydrogen production from natural gas steam reforming is shown in Figure 8. The key element of the freshwater eutrophication is the impact of the LPG production.

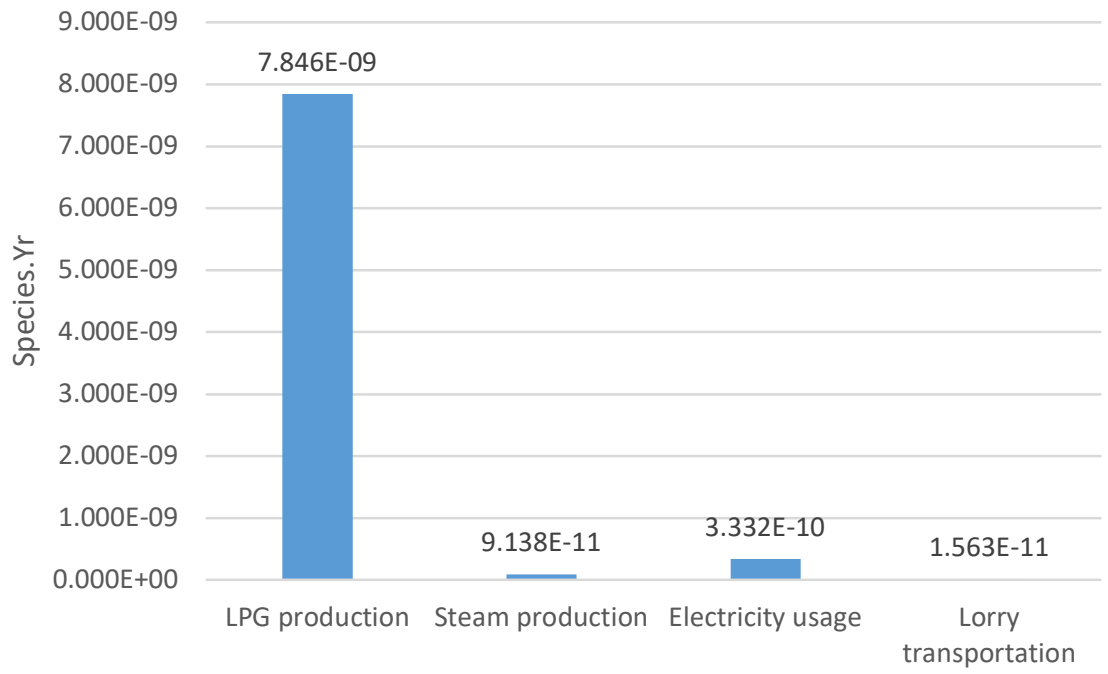

Figure 8. Freshwater eutrophication effect from hydrogen production from natural gas steam reforming.

\subsection{Comparison}

The comparison between the two processes is summarized in Table 5, and elaborated in the figures following.

Table 5. LCIA results for hydrogen production from biomass gasification and natural gas steam reforming. 


\begin{tabular}{cccc}
\hline $\begin{array}{c}\text { Global warming, } \\
\text { Human health }\end{array}$ & $2.14 \mathrm{E}-05$ & $1.05 \mathrm{E}-04$ & DALY \\
\hline $\begin{array}{c}\text { Terrestrial acidification } \\
\begin{array}{c}\text { Freshwater eutrophica- } \\
\text { tion }\end{array}\end{array}$ & $2.22 \mathrm{E}-08$ & $1.37 \mathrm{E}-07$ & Species.Yr \\
\hline
\end{tabular}

The comparison for Global warming is shown in Figure 9, Terrestrial acidification in Figure 10, and Freshwater eutrophication in Figure 11.

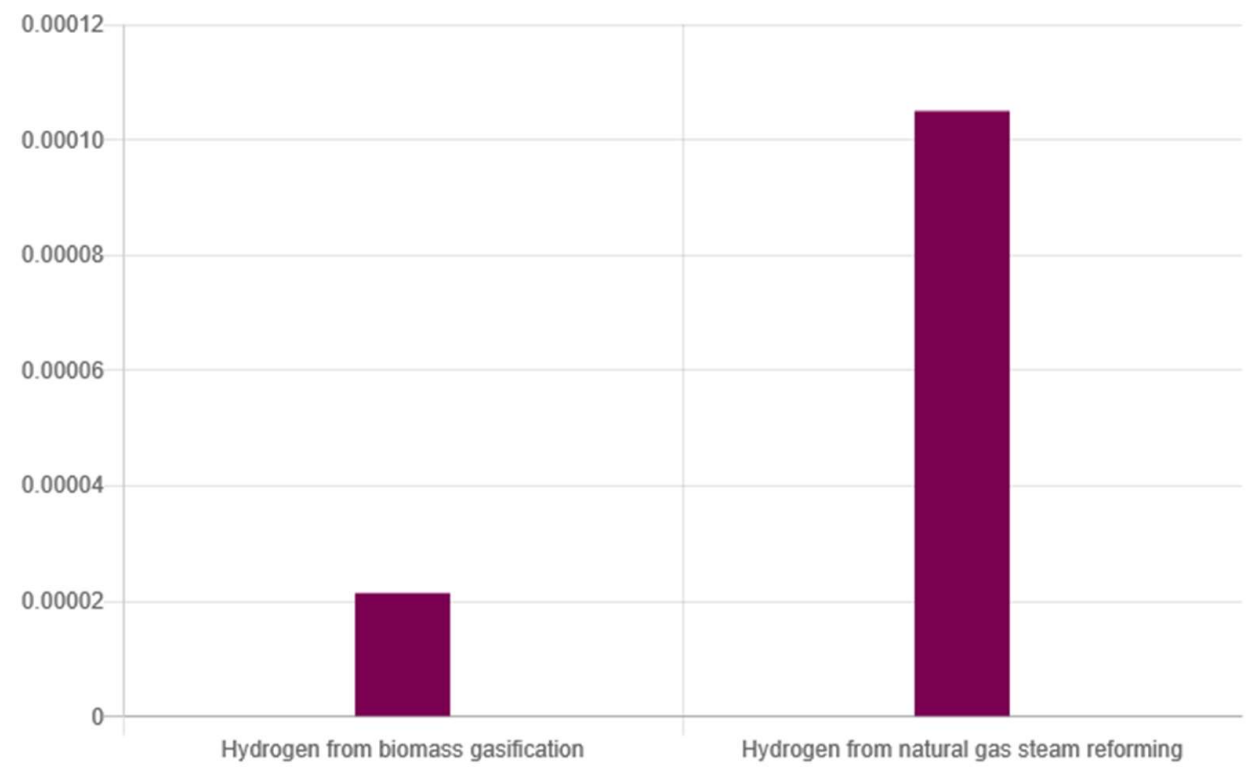

Figure 9. Global warming effect comparison between hydrogen production from biomass and natural gas. Vertical axis units are DALY. 


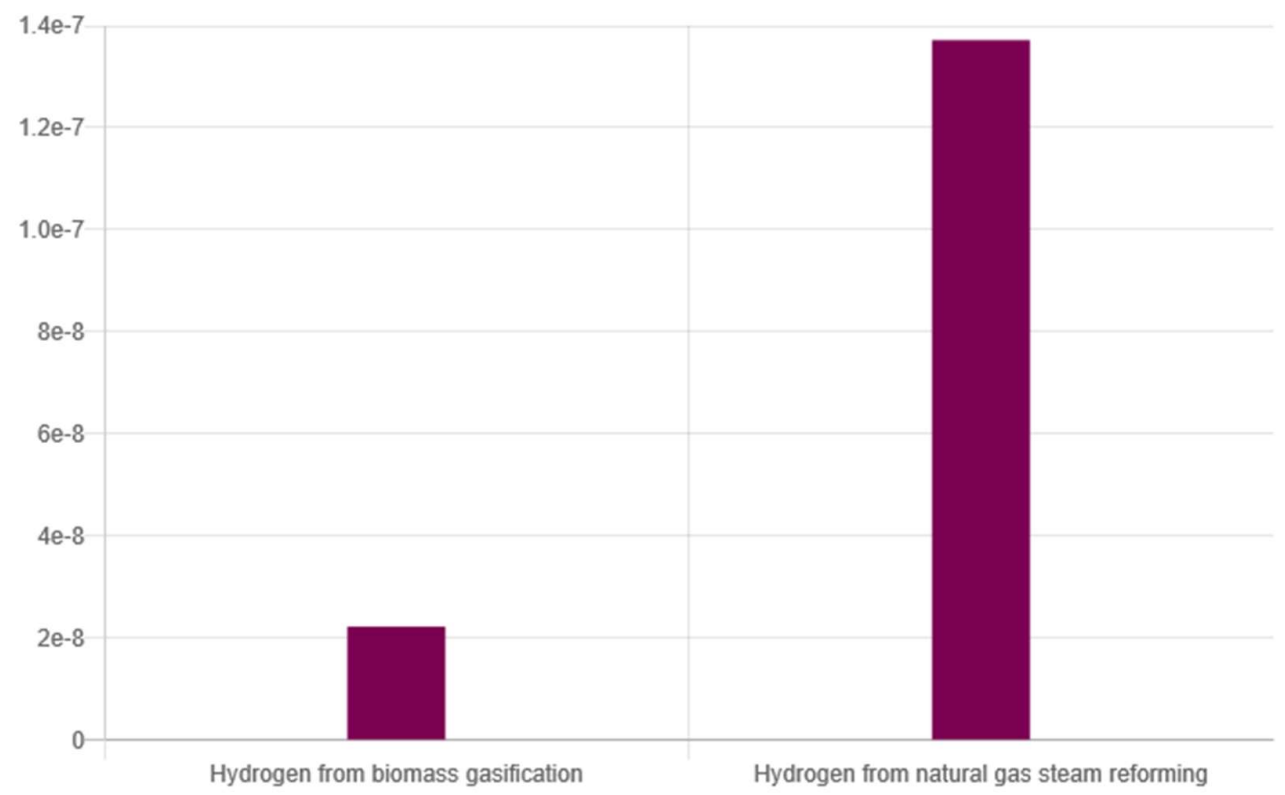

Figure 10. Terrestrial acidification effect comparison between hydrogen production from biomass and natural gas. Vertical axis units are species. Yr.

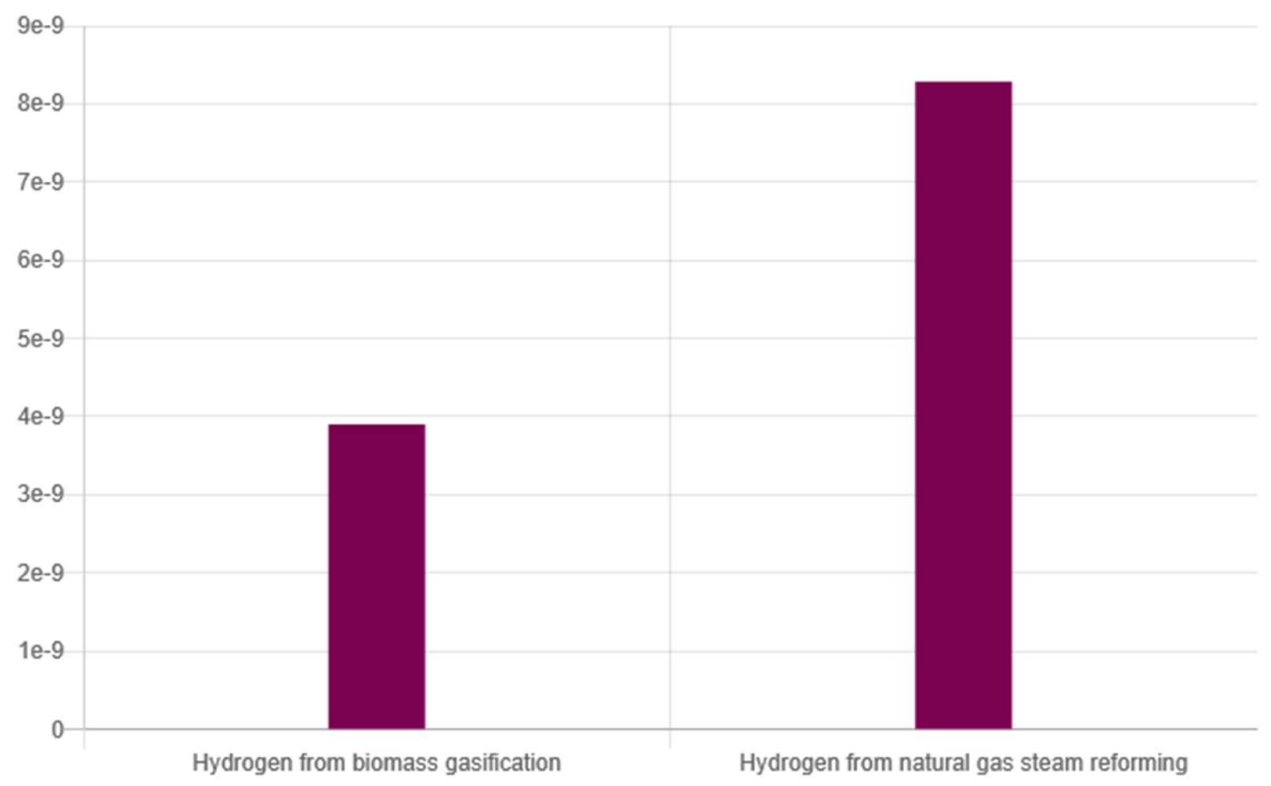

Figure 11. Freshwater eutrophication effect comparison between hydrogen production from biomass and natural gas. Vertical axis units are species. Yr.

The score for global warming of hydrogen production from biomass gasification is 2.14E-05 DALY while the score for global warming of hydrogen production from natural gas steam reforming is $1.05 \mathrm{E}-04$ DALY which is $391 \%$ higher. For the global warming effect of hydrogen production from biomass gasification, $73 \%$ of the total contribution is from the silica sand acquisition, $12 \%$ is from the wood pellet production, $6 \%$ is from the 
steam production, $9 \%$ is from the biomass gasification process and less than $1 \%$ is from the lorry transportation. For the global warming effect of hydrogen production from natural gas steam reforming, $92 \%$ of the total contribution is from the LPG extraction from fossil fuel, $7 \%$ is from the steam reforming process and less than $1 \%$ is from the sum of steam production, electricity generation and lorry transportation.

The score for the terrestrial acidification of the hydrogen production from biomass gasification is 2.22E-08 species. Yr, while the score for the terrestrial acidification of the hydrogen production from natural gas steam reforming is $1.37 \mathrm{E}-07$ species. Yr, which is $517 \%$ higher than the score of biomass gasification. For the terrestrial acidification of hydrogen production from biomass gasification, $85 \%$ of the total contribution is from the silica sand acquisition, $9 \%$ is from the wood pellet production, $5 \%$ is from the steam production, $1 \%$ is from the biomass gasification process and $0.1 \%$ is from the lorry transportation. For terrestrial acidification of hydrogen production from natural gas steam reforming, $99 \%$ of the total contribution is from the LPG extraction from fossil fuel and $1 \%$ is from the sum of steam production, steam reforming process, electricity generation and lorry transportation.

The score for freshwater eutrophication of the hydrogen production from biomass gasification is 3.90E-09 species. $\mathrm{Yr}$, while the score for freshwater eutrophication of the hydrogen production from natural gas steam reforming is $8.29 \mathrm{E}-09$ species. Yr, which is $113 \%$ higher than the score of biomass gasification. For the fresh eutrophication of the hydrogen production from biomass gasification, $77 \%$ of the total contribution is from the silica sand production, $18 \%$ is from the wood pellet production, $4 \%$ is from the steam production, $0.1 \%$ is from the lorry transportation. For fresh eutrophication from the hydrogen production from natural gas steam reforming, $95 \%$ of the total contribution is from the LPG extraction from fossil fuel, $1 \%$ is from the steam production, $4 \%$ is from the electricity usage and $0.2 \%$ is from the lorry transportation.

\section{Discussion}

\subsection{Findings and outcomes}

For all three metrics, biomass gasification has lower impacts than natural gas steam reforming, sometimes by large margins.

In the raw material acquisition section, for biomass gasification the silica sand production contributes most to all three impact categories, whereas for natural gas steam reforming it is the LPG extraction. In the case of New Zealand, the biomass might arise from forestry reside and organic household waste, and be relatively inexpensive. However a biomass gasification plant generally has a higher capital cost than a natural gas reforming plant, since the plant is expected to be larger with ancillary systems like electricity generation. The construction of plants is not covered in the present LCA system boundary.

\subsection{Implications for practitioners}

Hydrogen is an important material in an industrial economy, primarily as a feedstock for other downstream processes, and as a possible transitional fuel. The present analysis shows that hydrogen production from biomass gasification is environmentally better than from fossil fuel on all three metrics applied here. However, it is not devoid of impact. In particular, the acquisition of silica sand is the process where vigilance would be required.

Practitioners would be advised to consider the economics of plant construction, as this was excluded from the present study. In particular, the biomass plant is expected to be larger than regular hydrogen manufacturing plants, so the land usage should be considered with care. It would also be necessary to consider processes such as pre-treatment and gas cleaning. Production plants should be built near the source of biomass such as a 
forestry block, and near the location where input materials such as steam are easy to access.

\subsection{Limitations of the work}

The emission data of natural gas steam reforming covers a wide range of emission components, because natural gas steam reforming is a mature technology which has consistent process variables and a substantial literature. Hence we have higher confidence in the input and output flows for natural gas steam reforming, than for biomass gasification,

Biomass gasification is a relative new technology and the literature is sparse for emission data. The current life cycle assessment is based on a simplistic model of the biomass gasification and steam reforming process. For biomass gasification, various process setups such as different reactors and different gas cleaning components lead to different emission data. The best setup for biomass gasification is still under debate. Pre-treatment of raw material and downstream processing are not fully covered in the present analysis. For example, production of chemical materials used such as absorbents are not considered in the LCA model. Impacts analysed were $\mathrm{CO}_{2}, \mathrm{CH}_{4}, \mathrm{SO}_{x}, \mathrm{NO}_{x}, \mathrm{H}^{+}$and COD (chemical oxygen demand). Impacts from particle emission on human health were not included. Examples of excluded impact categories are human toxicity, photochemical oxidant formation, ozone depletion and water use.

\subsection{Future research opportunities}

Future research could focus on life cycle assessment of electricity in the New Zealand market. In the present analysis, we assumed the biomass gasification process to have an embedded electricity system, while the steam reforming process uses additional electricity supply based on the Australia market. For the New Zealand market, a high proportion of energy is generated from renewable energy sources and the LCA result for electricity usage is likely to be different under NZ situations.

The construction of plants based on New Zealand is another future research opportunity. Due to the scale difference of the plants, the final LCA result could be different.

\section{Conclusions}

Life cycle assessment results are reported for hydrogen production from steam reforming of natural gas, vs. biomass gasification. Impact on global warming, terrestrial acidification and freshwater eutrophication are quantified. This work found that the biomass route was better on all three metrics, and most especially on global warming.

For biomass gasification the major contribution to global warming, terrestrial acidification and freshwater eutrophication is silica sand production. For the steam reforming process it is the natural gas production.

The present analysis focussed on the environmental emissions due to plant operation, and excluded plant construction. A holistic analysis of a technology route, whether biomass or steam reforming, would need to also consider the specific process variants, construction costs, production settings, logistics of acquisition of input materials and delivery of outputs, plant economics, and market for the output product.

Author Contributions: Conceptualization, A.T and D.P.; methodology, A.T., D.P. and P.Z.; software, A.T. and P.Z.; validation, P.Z. and A.T.; formal analysis, A.T. and P.Z.; investigation, A.T., D.P. and P.Z.; resources, D.P.; data curation A.T. and P.Z.; writing-original draft preparation, P.Z., A.T. and D.P.; writing - review and editing, A.T. and D.P.; visualization, A.T., P.Z.; supervision, A.T. and D.P.; project administration, A.T. and D.P.; funding acquisition, D.P. All authors have read and agreed to the published version of the manuscript. 
Acknowledgments: Christine Walker, University of Canterbury, for helping with language and style.

Conflicts of Interest: The authors declare no conflict of interest.

\section{References}

1. IEA, Key World Energy Statistics 2020. IEA, Paris 2020.

2. Bilgen, S., Structure and environmental impact of global energy consumption. Renewable and Sustainable Energy Reviews, 2014. 38: p. 890-902.

3. Molino, A., Chianese, S., and Musmarra, D., Biomass gasification technology: The state of the art overview. Journal of Energy Chemistry, 2016. 25(1): p. 10-25.

4. Kirkels, A.F. and Verbong, G.P., Biomass gasification: Still promising? A 30-year global overview. Renewable and Sustainable Energy Reviews, 2011. 15(1): p. 471-481.

5. Koroneos, C., Dompros, A., and Roumbas, G., Hydrogen production via biomass gasification-A life cycle assessment approach. Chemical Engineering and Processing: Process Intensification, 2008. 47(8): p. 1261-1268.

6. Koroneos, C., Dompros, A., Roumbas, G., and Moussiopoulos, N., Life cycle assessment of hydrogen fuel production processes. International journal of hydrogen energy, 2004. 29(14): p. 1443-1450.

7. Puig-Arnavat, M., Bruno, J.C., and Coronas, A., Review and analysis of biomass gasification models. Renewable and sustainable energy reviews, 2010. 14(9): p. 2841-2851.

8. Gassner, M., Process design methodology for thermochemical production of fuels from biomass. 2010, EPFL.

9. Rupar, K. and Sanati, M., The release of organic compounds during biomass drying depends upon the feedstock and/or altering drying heating medium. Biomass and Bioenergy, 2003. 25(6): p. 615-622.

10. Holmberg, H. and Ahtila, P., Evaluation of energy efficiency in biofuel drying by means of energy and exergy analyses. Applied Thermal Engineering, 2005. 25(17-18): p. 3115-3128.

11. Kalinci, Y., Hepbasli, A., and Dincer, I., Life cycle assessment of hydrogen production from biomass gasification systems. International journal of hydrogen energy, 2012. 37(19): p. 14026-14039.

12. Salkuyeh, Y.K., Saville, B.A., and MacLean, H.L., Techno-economic analysis and life cycle assessment of hydrogen production from different biomass gasification processes. International Journal of Hydrogen Energy, 2018. 43(20): p. 9514-9528.

13. Haryanto, A., Fernando, S., Murali, N., and Adhikari, S., Current status of hydrogen production techniques by steam reforming of ethanol: a review. Energy \& Fuels, 2005. 19(5): p. 2098-2106.

14. Spath, P.L. and Mann, M.K., Life cycle assessment of hydrogen production via natural gas steam reforming. 2000, National Renewable Energy Lab., Golden, CO (US).

15. Nikolaidis, P. and Poullikkas, A., A comparative overview of hydrogen production processes. Renewable and sustainable energy reviews, 2017. 67: p. 597-611.

16. Dagle, R., Dagle, V., Bearden, M., Holladay, J., Krause, T., and Ahmed, S., RED opportunities for development of natural gas conversion technologies for co-production of hydrogen and value-added solid carbon products. Argonne National Lab Report, 2017 DOI: https://doi.org/10.2172/1411934.

17. Roh, H.-S., Lee, D.K., Koo, K.Y., Jung, U.H., and Yoon, W.L., Natural gas steam reforming for hydrogen production over metal monolith catalyst with efficient heat-transfer. International journal of hydrogen energy, 2010. 35(4): p. 1613-1619.

18. Iulianelli, A., Liguori, S., Wilcox, J., and Basile, A., Advances on methane steam reforming to produce hydrogen through membrane reactors technology: A review. Catalysis Reviews, 2016. 58(1): p. 1-35.

19. Cetinkaya, E., Dincer, I., and Naterer, G., Life cycle assessment of various hydrogen production methods. International journal of hydrogen energy, 2012. 37(3): p. 2071-2080 DOI: https://doi.org/10.1016/j.ijhydene.2011.10.064. 
20. Marquevich, M., Sonnemann, G.W., Castells, F., and Montané, D., Life cycle inventory analysis of hydrogen production by the steam-reforming process: comparison between vegetable oils and fossil fuels as feedstock. Green Chemistry, 2002. 4(5): p. 414-423.

21. Suleman, F., Dincer, I., and Agelin-Chaab, M., Comparative impact assessment study of various hydrogen production methods in terms of emissions. International Journal of Hydrogen Energy, 2016. 41(19): p. 8364-8375.

22. Dufour, J., Serrano, D.P., Gálvez, J.L., Moreno, J., and González, A., Hydrogen production from fossil fuels: life cycle assessment of technologies with low greenhouse gas emissions. Energy \& Fuels, 2011. 25(5): p. 2194-2202.

23. Salkuyeh, Y.K., Saville, B.A., and MacLean, H.L., Techno-economic analysis and life cycle assessment of hydrogen production from natural gas using current and emerging technologies. International Journal of hydrogen energy, 2017. 42(30): p. 18894-18909 DOI: https://doi.org/10.1016/j.ijhydene.2017.05.219. 